\title{
INFLUENCE OF CURING TEMPERATURE ON THERMAL PROPERTIES AND UV STABILITY OF HYDROXYPROPYL CELLULOSE CROSS-LINKED WITH GLYOXYLIC ACID
}

\author{
MAREN FREESE, ${ }^{*}$ AMREI MENSCH, ${ }^{*}$ MARTINA BREMER, ${ }^{*}$ JENS SCHALLER, $^{* *}$ \\ MICHAEL SCHÖBITZ** and STEFFEN FISCHER ${ }^{*}$ \\ *Institute of Plant and Wood Chemistry, Technische Universität Dresden, 19, Pienner Str., \\ 01737 Tharandt, Germany \\ ***Thuringian Institute for Textile and Plastics Research, Breitscheidstraße 97, \\ 07407 Rudolstadt, Germany \\ \Corresponding author: Steffen Fischer, sfischer@forst.tu-dresden.de
}

Received February 15, 2019

Hydroxypropyl cellulose (HPC) can be cross-linked to films by means of glyoxylic acid. The cross-linking temperature (room temperature up to $100^{\circ} \mathrm{C}$ ) influences the thermal and mechanical properties of the formed films, in which the impact on the tensile strength is higher than that on the thermal stability. A temperature of $70{ }^{\circ} \mathrm{C}$ can be specified as optimal cross-linking temperature. In addition to the thermal and mechanical properties, the UV stability of the films is investigated by UV-GC/MS.

Artificial aging of the films indicates a degradability of the cross-linked HPC films. The lower the cross-linking temperature of the HPC films, the faster is the degradation caused by artificial aging.

Keywords: hydroxypropyl cellulose, cross-linking, UV degradation, artificial weathering, UV-GC/MS

\section{INTRODUCTION}

Hydroxypropyl cellulose (HPC) is a cellulose ether, which is widely used in many technical applications. Owing to its dissolution properties in both aqueous and aprotic solvents, HPC is applicable, for instance, as food additive, thickener or emulsion stabilizer. Furthermore, HPC may also act as distributor in pharmaceutical formulations. Thus, it is commonly used as binder for the production of tablets by the wet granulation method. ${ }^{1}$ The applications of HPC can be extended if the polymer is cross-linked. In general, two options have to be differentiated: cross-linking by high-energy radiation or by chemical agents. Acrylic esters based on HPC can be synthesized, for instance, by cross-linking using ultraviolet (UV) radiation. ${ }^{2}$ Chemical crosslinking of HPC can be carried out, for example, with poly ethylene oxides. These materials are of interest for use as polymer electrolytes. ${ }^{3}$ However, cross-linkers, which include aldehyde functions, are used most commonly. Crosslinking of polyalcohols using bi-functional aldehydes, e.g. glutardialdehyde, is an established method in industrial cellulose fibre treatment. ${ }^{4}$ The basic reaction is the acetal formation. This reaction is also, in the case of cellulose ethers, highly efficient due to the hydroxyl groups in the side chains of the cellulose ether. Cross-linking of HPC became a subject of extensive investigations since HPC turned out to be the most suitable cellulose ether for this reaction. Most of them deal with the formation and properties of films of liquid crystal solutions and focus on the outstanding swelling behaviour in water. ${ }^{5-7}$

The results have led to the idea of establishing HPC films for ground covering. The cross-linking reaction is independent of an additional initiation, e.g. drying after spreading onto the soil, although the rate of conversion strongly depends on ambient conditions, such as temperature and humidity. Being exposed to occasionally harsh environmental conditions, the foils need to be mechanically stable.

The object of this study is the influence of curing conditions on the mechanical, thermal and UV stability of the resulted HPC films. HPC was 
cross-linked by glyoxylic acid at different temperatures. Afterwards, an artificial aging was conducted for several times. Thermal stability and mechanical strength were determined. In addition, $\mathrm{UV}-\mathrm{GC} / \mathrm{MS}$ is a suitable method to investigate the weathering stability of polymer films. It is a coupled analysis method, where the polymer sample is exposed to UV radiation and the emitted substances are collected in a cryo-cooling trap and then transferred directly to the GC/MS. ${ }^{8}$

\section{EXPERIMENTAL}

Materials, film formation and artificial weathering

An aqueous solution of hydroxypropyl cellulose, glyoxylic acid as cross-linker and benzoic acid as stabilizing additive, in the proportion of 1:0.4:0.006, was treated by ultrasound (ultrasonic bath Bandelin Sonorex RK100) for 10 minutes to remove air bubbles from the solution. Afterwards, the solution was carefully poured into a planar glass bowl to avoid new air bubbles and was dried at room temperature (RT) for 48 hours. The received film was supposed to have a thickness of about $0.5 \mathrm{~mm}$ after desiccation. Then, the films were removed from the glass bowl and were cut in stripes with a length of $135 \mathrm{~mm}$ and a width of 15 $\mathrm{mm}$. Additionally, a part of the stripes were annealed at temperatures of $40{ }^{\circ} \mathrm{C}, 70{ }^{\circ} \mathrm{C}$ and $100{ }^{\circ} \mathrm{C}$ for 24 hours in a drying oven to examine the influence of the temperature on the linkage.

In order to assess the resistance to UV light, the films were artificially weathered by a xenon weathering instrument (Heraeus, Xenotest ${ }^{\circledR}$ 150S). The weathering conditions of outdoor sunlight were chosen. For this purpose, six infrared (IR) filters and one UV filter were arranged around the xenon lamp and irradiance 2 was set for adjusting to outdoor conditions. Periods of 125 hours, 250 hours and 500 hours were defined for artificial weathering.

\section{Characterization}

The samples, which were cured at different temperatures and weathered artificially, were analysed by thermal analysis, strength analysis, FT-Raman, as well as FTIR spectroscopy and UV-GC/MS.

\section{Differential scanning calorimetry (DSC) and thermogravimetry (TG)}

The thermal behaviour of the films was analysed by STA 449 F5 Jupiter (Netzsch) under nitrogen atmosphere (flow: $20 \mathrm{~mL} / \mathrm{min}$ ) with a heating rate of $10 \mathrm{~K} / \mathrm{min}$ up to $550{ }^{\circ} \mathrm{C}$. Between 10 and $15 \mathrm{mg}$ of the samples were used for this analysis.

\section{Tensile strength tests}

The HPC film stripes, with and without artificial weathering, were tested for their mechanical properties in a Hegewald \& Peschke Inspekt 10 device. The stripes with a length of $135 \mathrm{~mm}$ and a width of $15 \mathrm{~mm}$ were placed in the device with a clamping length of $80 \mathrm{~mm}$. They were pulled apart in vertical direction at a feed rate of $5 \mathrm{~mm} / \mathrm{min}$. The pre-power was $5 \mathrm{~N}$. Six stripes of each sample were examined.

\section{FT-Raman and FTIR spectroscopy}

For the investigations, the Raman MultiRAMII spectrometer (Bruker Optics, resolution: $4 \mathrm{~cm}^{-1}$, power: $250 \mathrm{~mW}$, number of scans: 200) was used. The laser source is a standard diode-pumped, air-cooled $\mathrm{Nd}$ :YAG laser (1064 nm). The system is equipped with a proprietary high-sensitivity Ge diode detector. The spectral range was between 3600 and $50 \mathrm{~cm}^{-1}$. The IR spectra were recorded with a Tensor27 FTIR spectrometer (Bruker Optics, resolution: $4 \mathrm{~cm}^{-1}$, number of scans: 32), using the ATR technique.

\section{UV-gas chromatography/mass spectrometry (UV- GC/MS)}

UV-GC/MS is a coupling of a gas chromatographymass spectrometry system and a micro-UV lamp (UV1074Xe, FRONTIER Labs). ${ }^{9}$ Volatile compounds and photochemical degradation products were released by the online UV irradiation $(\mathrm{t}=30 \mathrm{~min}, \lambda=208-450 \mathrm{~nm})$ and then collected by a cryo-cooling trap (MicroJet Cryo-Trap MJT-1035E, SIM). Subsequently, these substances were transferred onto the column system (column: JW DB-1 $30 \mathrm{~m} \times 250 \mu \mathrm{m} \times 0.25 \mu \mathrm{m}$ ) of a GC/MS instrument (GC 7890B/MSD 5977, AGILENT Technologies). The used carrier gas was He, with a flow rate of $1 \mathrm{~mL} / \mathrm{min}^{-1}$. There are two steps in the temperature program: 1) $40{ }^{\circ} \mathrm{C}$ to $100{ }^{\circ} \mathrm{C}$, with a heating rate of $5 \mathrm{~K} / \mathrm{min}$; 2) $100{ }^{\circ} \mathrm{C}$ to $280{ }^{\circ} \mathrm{C}$, with a heating rate of $30 \mathrm{~K} / \mathrm{min}$.

\section{RESULTS AND DISCUSSION}

The films were formed at RT and annealed at $40{ }^{\circ} \mathrm{C}, \quad 70{ }^{\circ} \mathrm{C}$ and $100{ }^{\circ} \mathrm{C}$, as described. To perceive the influence of the curing temperature on the cross-linking, at first the films without weathering were investigated by thermal analysis (DSC and TG).

In Figure 1a, the DSC curve of the film dried at RT can be seen. There are four separate temperature ranges. Two of them show respective peak minima $\left(325.9^{\circ} \mathrm{C}, 397.7^{\circ} \mathrm{C}\right)$. Between these peaks, two very broad effects can be observed. These effects are caused by the pure HPC. Already at a curing temperature of $40{ }^{\circ} \mathrm{C}$, the minima cannot be identified anymore. The sample cross-linked at $70{ }^{\circ} \mathrm{C}$ shows a similar DSC curve. On the contrary, the DSC curve of the film with a curing temperature of $100{ }^{\circ} \mathrm{C}$ shows two sharp endothermic effects. The DSC measurements show that with increasing the curing temperature, less sharp signals are initially detectable. However, the detected signals are most 
pronounced at the highest curing temperature. Sharp peaks suggest an increasingly ordered structure at $100{ }^{\circ} \mathrm{C}$ curing temperature, caused by a higher degree of cross-linking in the formed films. This was confirmed by the swelling experiments in water. The higher the curing temperature of the sample, the lower is the swelling ability. Further, it is noticed that the cross-linking at $40{ }^{\circ} \mathrm{C}$ and $70{ }^{\circ} \mathrm{C}$ does not lead to significant differences in the DSC curves, which indicates similarly cross-linked structures.

In Figure 1b, the TG curves of the unweathered films of the four different curing temperatures are shown. Two different temperature ranges for mass loss were found. Substances of low molecular weight were decomposed in the first range up to $225^{\circ} \mathrm{C}$. Unbound cross-linking agents are decomposed in this range. The boiling point of benzoic acid is at $250{ }^{\circ} \mathrm{C}$. A decrease in the mass loss with rising cross-linking temperature was found. The sample cross-linked at $100{ }^{\circ} \mathrm{C}$ has the lowest mass loss of $5.5 \%$. The largest difference in mass loss was obtained between $100{ }^{\circ} \mathrm{C}$ and $70{ }^{\circ} \mathrm{C}$ curing temperature $(2.1 \%)$. Mass losses of the samples cured between RT and $70{ }^{\circ} \mathrm{C}$ are similar. Hence, this also indicates a stronger cross-linking after annealing at $100{ }^{\circ} \mathrm{C}$, because of the lower amount of unbound cross-linking agent.

In the second temperature range, above $225^{\circ} \mathrm{C}$, the decomposition of high molecular and cross-linked HPC and the evaporation of unbound benzoic acid took place. Hence, the effect should be generated mainly by polymer degradation because of the low content of benzoic acid. The film cross-linked at $100{ }^{\circ} \mathrm{C}$ shows the lowest mass loss even at higher temperatures. Temperatures at which the mass loss reaches $5 \%$ in this step can be found in Table 1. The temperatures increase corresponding to the cross-linking rate. The sample with a curing temperature of $100{ }^{\circ} \mathrm{C}$ reaches the mass loss of $5 \%$ at the highest temperature. Contrary to the first decomposition step, the largest temperature difference is observed for the samples cured between RT and $40{ }^{\circ} \mathrm{C}$.

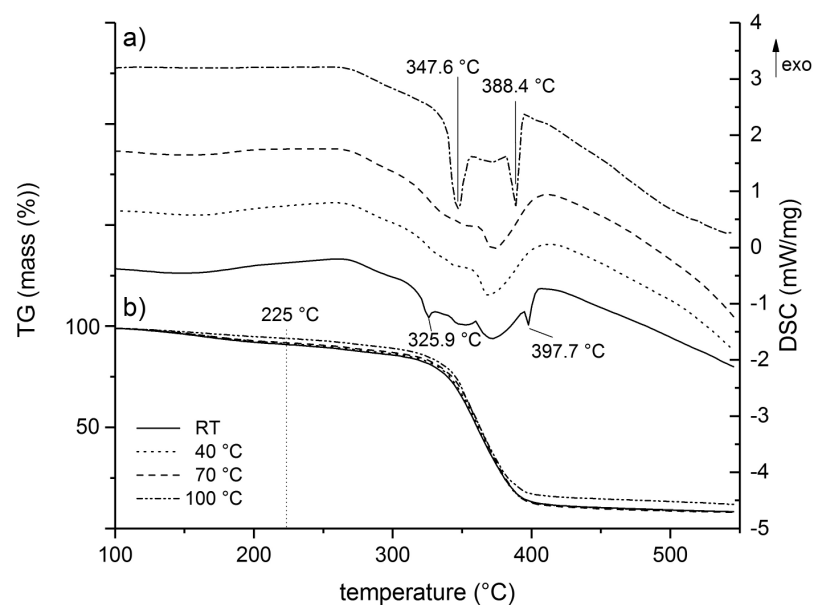

Figure 1: Thermogravimetric analysis of HPC films cross-linked at RT, $40{ }^{\circ} \mathrm{C}, 70{ }^{\circ} \mathrm{C}$ and $100{ }^{\circ} \mathrm{C}$ without weathering;

(a) differential scanning calorimetry (DSC), (b) thermogravimetry (TG)

Table 1

Temperatures at which $5 \%$ mass loss was reached as a polymer decomposition step

\begin{tabular}{ccc}
\hline $\begin{array}{c}\text { Curing temperature } \\
\left({ }^{\circ} \mathrm{C}\right)\end{array}$ & $\begin{array}{c}\text { Weathering time } \\
(\mathrm{h})\end{array}$ & $\begin{array}{c}\text { 5\% Mass loss } \\
\text { temperature }\left({ }^{\circ} \mathrm{C}\right)\end{array}$ \\
\hline 20 & 0 & 240 \\
40 & 0 & 290 \\
70 & 0 & 290 \\
100 & 0 & 298 \\
70 & 125 & 267 \\
70 & 250 & 264 \\
70 & 500 & 252 \\
\hline
\end{tabular}




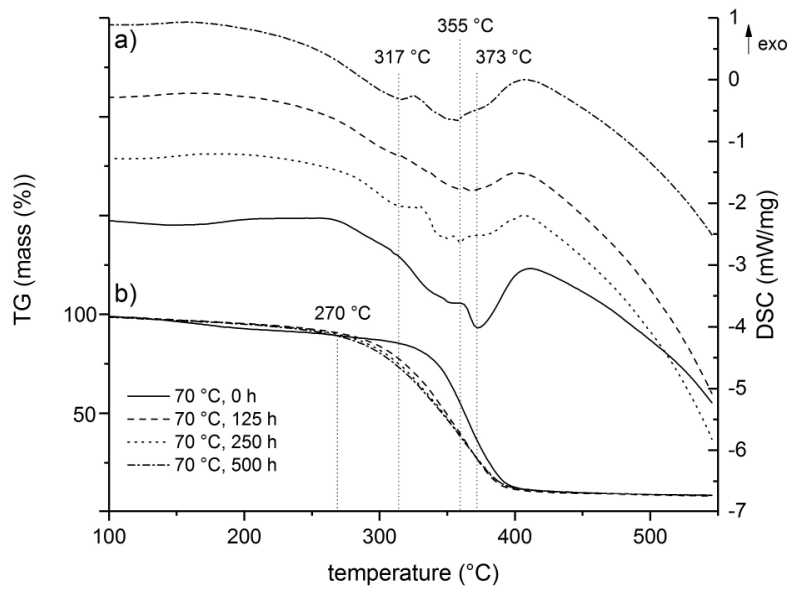

Figure 2: Thermogravimetric analysis curves of films cross-linked at $70{ }^{\circ} \mathrm{C}$ and artificially weathered for $125 \mathrm{~h}, 250 \mathrm{~h}$ and $500 \mathrm{~h}$; (a) differential scanning calorimetry (DSC), (b) thermogravimetry (TG)

The thermal analysis points out a higher degree of cross-linking with increasing temperature during cross-linking and therefore, an increasing thermal stability. This was confirmed by considering the morphology of the formed films. It was observed that the films cured at RT, $40{ }^{\circ} \mathrm{C}$ and $70{ }^{\circ} \mathrm{C}$ are flexible and elastic, whereby the flexibility decreases with rising curing temperature. The films cross-linked at $100{ }^{\circ} \mathrm{C}$ are very rigid and brittle. Therefore, they were not suitable for further investigations.

Artificial aging was carried out for the samples cross-linked at $70{ }^{\circ} \mathrm{C}$ in order to investigate the influence of UV radiation on the thermal properties of the films. Thereafter, the samples were examined by thermal analysis. Figure $2 \mathrm{a}$ shows the DSC curves of the films after 125 hours, 250 hours and 500 hours of artificial weathering, in comparison to those of a sample without weathering. A broadening of the DSC effects with increasing weathering time is shown. There is also a slight shift of the peak minima (endothermal effect) to lower temperatures. This indicates a degradation of the cross-linked polymer with increasing weathering time.

A change in the thermal properties after weathering can also be seen in the TG curves. A difference in weight loss between the unweathered film and the weathered films was observed in the temperature range up to $270{ }^{\circ} \mathrm{C}$. The sample without weathering shows a weight loss a little higher than the weathered samples. With increasing weathering time, the mass loss became smaller. As mentioned before, the mass loss in this range can be explained by the decomposition of unbound cross-linker (glyoxalic acid). This was confirmed by comparing the measurements of the pure HPC, which shows no weight loss in this temperature range. The results point out a further reaction of the cross-linking agent initiated by the UV beam.

In the second range, above $270{ }^{\circ} \mathrm{C}$, degradation of the polymer occurs. The temperature at which the mass loss reaches $5 \%$ goes down with increasing weathering time (Table 1). The most significant change is between the unweathered film and the film weathered for $125 \mathrm{~h}$. With extended weathering, the decomposition behaviour changes only slightly (Fig. 2b). This indicates a slow progressive degradation of the polymer during weathering. The results of the thermal analyses of the weathered samples indicate two parallel processes. On the one hand, there is a UVindexed cross-linking, which should lead to an improvement of the thermal stability. On the other hand, the (cross-linked) HPC is degraded, which reduces the thermal stability of the films. The second effect predominates.

Mechanical properties confirm the results of thermal analysis. The stress-strain curves of selected samples are exemplarily shown in Figure 3. Before weathering, the sample annealed at $70{ }^{\circ} \mathrm{C}$ shows a significantly higher stiffness than the samples cross-linked at lower temperatures (Fig. 3a). As seen in Figure 4, the unweathered films showed different tensile strengths depending on the curing temperature. The highest tensile strength of $171 \mathrm{~N}$ was obtained for the film with a curing temperature of $70^{\circ} \mathrm{C}$. The samples crosslinked at RT and $40^{\circ} \mathrm{C}$ show comparatively low tensile strength values. This indicates that there is 
a much lower rate of cross-linking at curing temperatures of $\mathrm{RT}$ and $40{ }^{\circ} \mathrm{C}$. The stiffness of the samples cross-linked at low temperatures increases significantly after weathering for $125 \mathrm{~h}$
(Fig. 3b). However, this first period of artificial weathering leads to an increase of tensile strength in all the samples (Fig. 4).
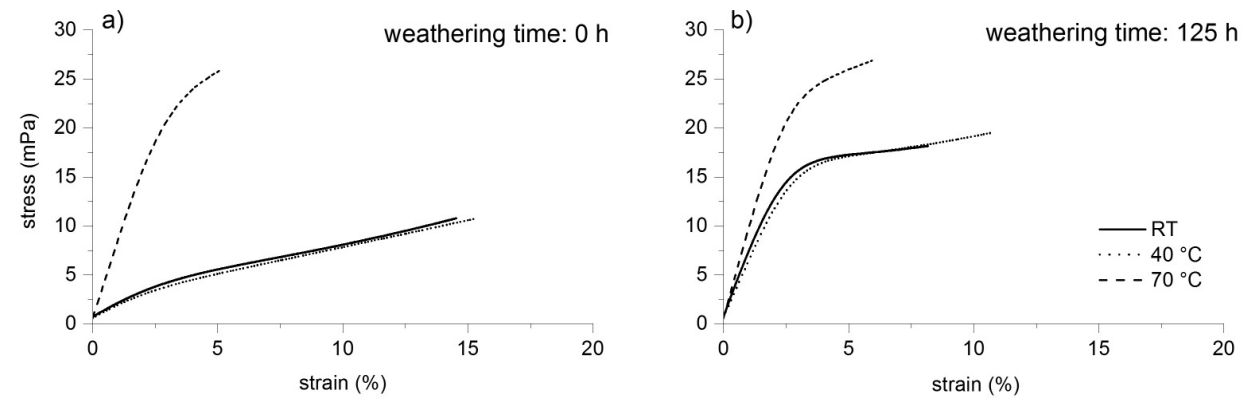

Figure 3: Stress-strain curve of unweathered samples (a) and the samples weathered for 125 hours (b)

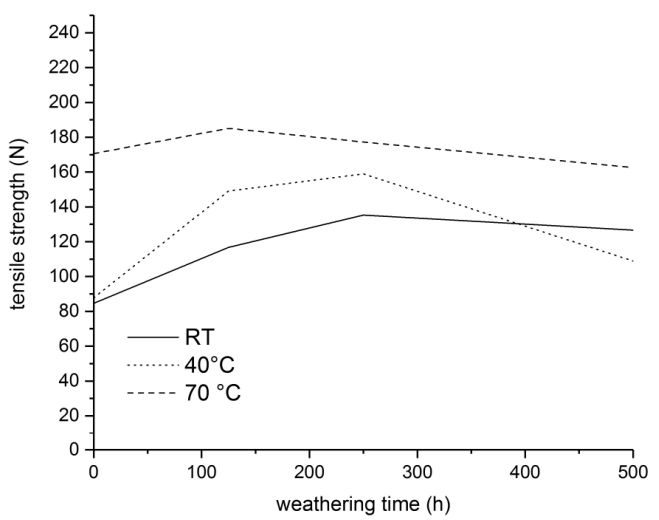

Figure 4: Impact of curing temperature and artificial weathering on the tensile strength of the formed films

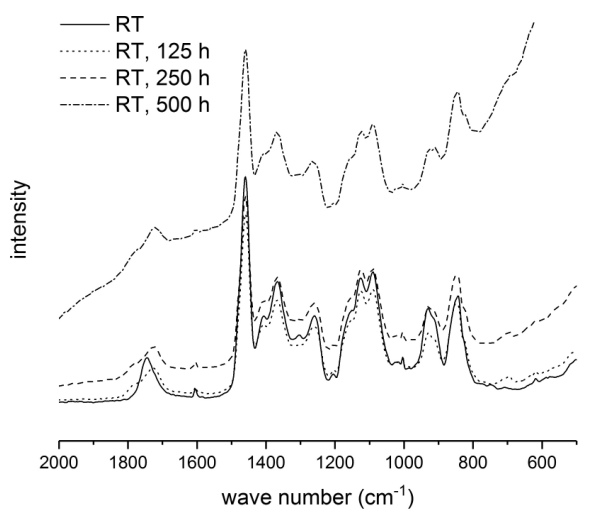

Figure 5: Raman spectra of films cross-linked at RT and artificially weathered for $125 \mathrm{~h}, 250 \mathrm{~h}$ and $500 \mathrm{~h}$

This confirms further cross-linking in accordance to the results of thermal analysis. The increase is lower if the film was previously crosslinked at higher temperature. The second period

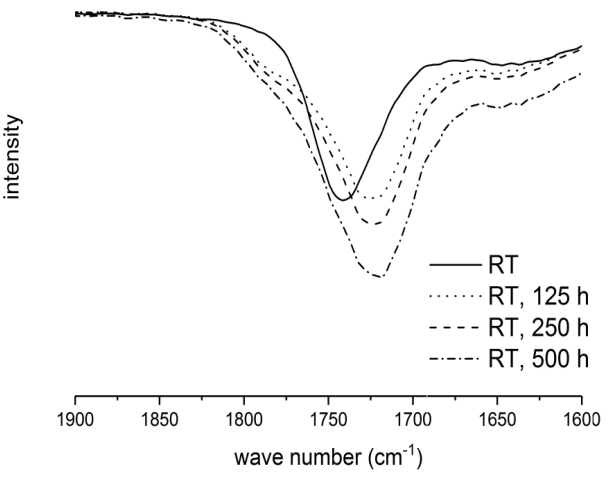

Figure 6: IR spectra in the range of $1.900-1.600 \mathrm{~cm}^{-1}$ of films dried at RT and artificially weathered for $125 \mathrm{~h}, 250 \mathrm{~h}$ and $500 \mathrm{~h}$

of weathering $(250 \mathrm{~h})$ leads to a further increase in the tensile strength of the films formed at lower temperatures (RT and $40{ }^{\circ} \mathrm{C}$ ). After $500 \mathrm{~h}$ of artificial weathering, the tensile strength of all the 
films decreases, since the oxidative polymer degradation is already advanced.

In order to study the structural changes of the films during weathering, FT-Raman and FTIR spectra were recorded after different weathering times. All the films annealed at different temperatures show differences in Raman spectra depending on the weathering time. As an example, Figure 5 shows the Raman spectra of films cross-linked at RT and artificially weathered for $125 \mathrm{~h}, 250 \mathrm{~h}$ and $500 \mathrm{~h}$.

One indication of a chemical change of the HPC films upon artificial weathering is an increase of fluorescence with longer weathering times, recognisable by an increase of the background of the Raman curves. However, there is a difference in the intensity of the increase. It is less strong at higher curing temperatures of the films.

Furthermore, a shift of the peak at a wavenumber of approximately $1745 \mathrm{~cm}^{-1}$ can be observed. This band can be assigned to the $\mathrm{CO}$ stretching vibration of glyoxylic acid, which is involved in acetal formation of cross-linking. ${ }^{10}$ CO stretching vibrations are more visible in IR spectra. Figure 6 shows the region of the $\mathrm{CO}$ stretching vibrations of the IR spectra of the same samples. It can be seen that there is no shift of the peak. An additional peak is created, which overlays the existing one. This makes the peak much broader. The additional peak is caused by the formation of aryl aldehydes by oxidation of the hydroxypropyl side chain initiated by weathering.

Besides, a broadening of many peaks in the Raman spectra can be observed with increasing weathering time. It indicates an increasing structural degradation of the polymeric structure in the film.

For further investigations, the light induced decomposition of the HPC films was analysed via UV-GC/MS. Figure 7 shows the chromatograms of unweathered samples cross-linked at RT, $40{ }^{\circ} \mathrm{C}$ and $70{ }^{\circ} \mathrm{C}$. The peak at a retention time of $4.9 \mathrm{~min}$ represents benzoic acid. The amount of benzoic acid decreases with increasing curing temperature. This indicates chemical bonding of the benzoic acid to the cellulose derivate film at higher cross-linking temperatures.

The influence of weathering time on the resistance to UV light of HPC films cross-linked at $\mathrm{RT}$ and $70^{\circ} \mathrm{C}$ is shown in Figure 8. For the interpretation of the chromatograms, it should be considered that substances that escape during artificial weathering via Xenotest ${ }^{\circledR}$ could not be detected via $\mathrm{UV}-\mathrm{GC} / \mathrm{MS}$.

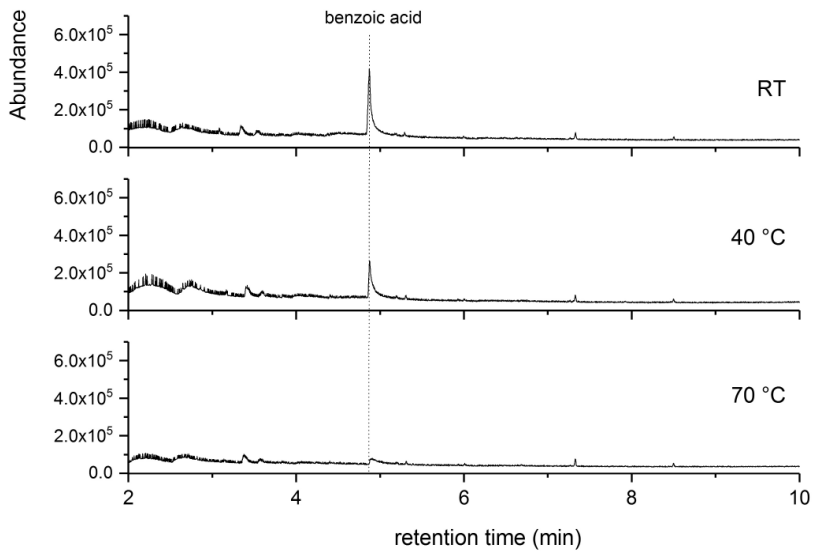

Figure 7: Chromatograms obtained over UV-GC/MS of unweathered HPC films cross-linked at RT, $40{ }^{\circ} \mathrm{C}$ and $70{ }^{\circ} \mathrm{C}$

The chromatograms only show volatile substances, which were collected during further irradiation via the UV-module for 30 minutes. The results show that benzoic acid can be used as an indicator for the cross-linking of the HPC films, although it is not a cross-linker itself. However, benzoic acid is involved more in the structure of the film when forming the films at a curing temperature of $70{ }^{\circ} \mathrm{C}$. Thereby, a smaller amount of benzoic acid can be obtained by UVGC/MS at this temperature. The film cross-linked at RT without artificial weathering shows the most pronounced benzoic acid peak after online micro-UV irradiation. The peak decreases after weathering because a part of the benzoic acid releases during the artificial weathering. In 
addition, the artificial weathering leads to a degradation of the cross-linked polymer. This causes more frequently occurring peaks in the front area (treat. $<4.5 \mathrm{~min}$ ) with increasing weathering. These peaks can be assigned to fragments of the hydroxypropyl cellulose chains. It becomes clear that the samples cross-linked at RT are more damaged and degraded by the weathering than the stronger cross-linked ones at $70{ }^{\circ} \mathrm{C}$.
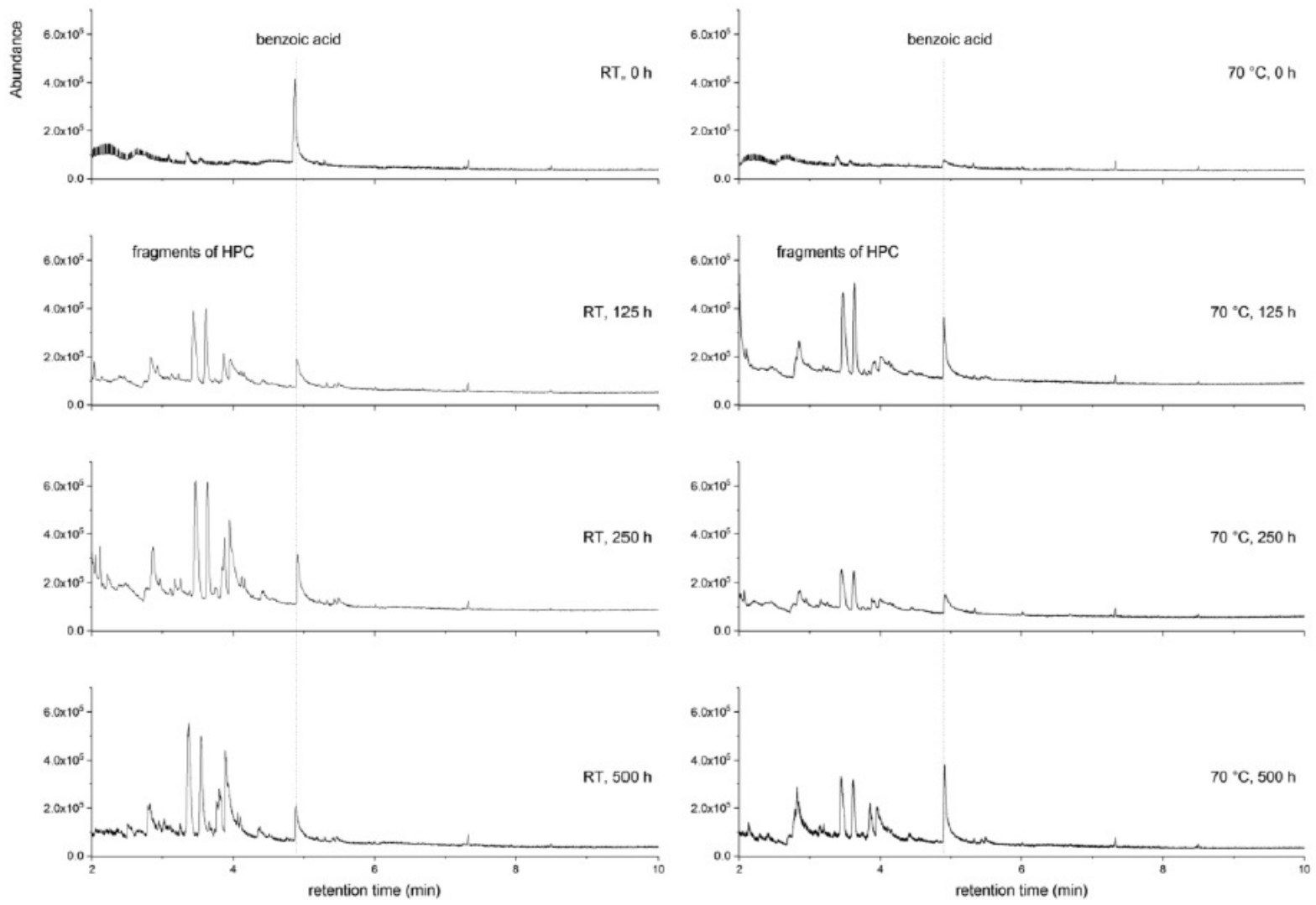

Figure 8: Chromatograms obtained over UV-GC/MS of weathered HPC films cross-linked at RT and $70{ }^{\circ} \mathrm{C}$

\section{CONCLUSION}

The cross-linking of HPC with glyoxylic acid allows the formation of stable films. The thermal and mechanical properties, as well as the UV stability, can be controlled via the cross-linking temperature. Above all, the thermal analyses indicate that a noticeable cross-linking takes place only at temperatures over $40^{\circ} \mathrm{C}$. If the crosslinking temperature increases, the thermal stability of the films increases as well. This is an indication of stronger cross-linking. However, the tensile strength of the sample cross-linked at $70{ }^{\circ} \mathrm{C}$ has the highest value. The films become more brittle if the cross-linking temperature rises. Hence, a cross-linking at $70{ }^{\circ} \mathrm{C}$ seems to be optimal considering all the analyses.
The cross-linking temperature also influences the weathering stability. An increase in the tensile strength of all the samples was obtained initially, which indicates further networking. Nevertheless, the strengths and the thermal stability decrease with increasing weathering time, which indicates a decomposition of the polymer. Nevertheless, the decrease of tensile strength starts later for the samples cross-linked at RT or $40{ }^{\circ} \mathrm{C}$.

An efficient method for monitoring crosslinking and thermal degradation is UV-GC/MS. Benzoic acid, which was added as a stabilizer against microorganisms, is incorporated more strongly into the structure if the cross-linking temperature increases. It was demonstrated, by comparing the aging under UV influence, that a 


\section{MAREN FREESE et al.}

higher cross-linking temperature results in stronger cross-linked films, which decay more slowly. This means that films based on HPC cross-linked with glyoxylic acid are degradable under UV radiation, and degradation can be controlled via the cross-linking temperature.

\section{REFERENCES}

1 T. Ishikawa, B. Mukai, S. Shiraishi, N. Utoguchi, M. Fujii et al., Chem. Pharmaceut. Bull., 49, 134 (2001), https://doi.org/10.1248/cpb.49.134

2 S. N. Bhadani and D. G. Gray, Mol. Cryst. Liq. Cryst., $\quad \mathbf{1 0 2}, \quad 255 \quad$ https://doi.org/10.1080/01406568408070536;

3 M. Chelmecki, W. H. Meyer and G. Wegner, $J$. Appl. Polym. Sci., 105, 25 (2007), https://doi.org/10.1002/app.26108

4 J. Schaller, K. Stengel, F. Meister and S. Riede, DE 102013005223 A1 (2013)
5 S. Suto, J. Appl. Polym. Sci., 37, 2781 (1989), https://doi.org/10.1002/app.1989.070370927

6 S. Suto and K. Suzuki, J. Appl. Polym. Sci., 55, 139 (1995), https://doi.org/10.1002/app.1995.070550116

S. Suto and K. Suzuki, Polymer, 38, 391 (1997), https://doi.org/10.1016/S0032-3861(96)00512-5

8 L. Passauer, M. Beyer, M. Freese, S. Fischer and J. Peters, "Book of Abstracts. $2^{\text {nd }}$ ETCC", Cologne (2014),

https://www.gdch.de/fileadmin/downloads/Netzwerk und_Strukturen/Fachgruppen/Lackchemie/ETCC_201 4_BoA_final.pdf

${ }^{-}$C. Watanabe, S. Tsuge and H. Ohtani, Polym. Degrad. Stabil., 94, $1467 \quad$ (2009), https://doi.org/10.1016/j.polymdegradstab.2009.05.005 10 G. Socrates, "Infrared and Raman Characteristic Group Frequencies", $3^{\text {rd }}$ ed., John Wiley \& Sons, Chichester, UK, 2001, https://doi.org/10.1021/ja0153520 